\title{
Correction to: A four-quadrant current multiplier/divider cell with four transistors
}

\author{
Ahmed Elwakil $^{1}$ (D) Brent Maundy ${ }^{2}$ (D) Mohammed Balla Elamien $^{2} \cdot$ Leonid Belostotski $^{2}$
}

Published online: 9 March 2018

(C) Springer Science+Business Media, LLC, part of Springer Nature 2018

\section{Correction to: Analog Integrated Circuits and Signal Processing} https://doi.org/10.1007/s10470-018-1122-8

The original version of this article unfortunately contained a mistake. The co-authors' affiliation details were incorrect in the original publication of this article.

The correct affiliation details are given below.

\begin{abstract}
Ahmed Elwakil
aselwakil@gmail.com

elwakil@ieee.org
\end{abstract}

The original article can be found online at https:// doi.org/10.1007/s10470-018-1122-8.

\footnotetext{
Ahmed Elwakil

aselwakil@gmail.com; elwakil@ieee.org

1 University of Sharjah, Sharjah, PO Box 27272, United Arab Emirates

2 Department of Electrical and Computer Engineering, University of Calgary, 2500 University Dr. NW, Calgary, AB T2N1N4, Canada
}

1 University of Sharjah, Sharjah, PO Box 27272, United Arab Emirates

2 Department of Electrical and Computer Engineering, University of Calgary, 2500 University Dr. NW, Calgary, AB T2N1N4, Canada. 